ERRATUM

J.P.L. Davis · P.F-W. Chien • A.R. Chipperfield

A. Gordon - A.A. Harper

\title{
The three mechanisms of intracellular chloride accumulation in vascular smooth muscle of human umbilical and placental arteries
}

Published online: 23 September 2000

(C) Springer-Verlag 2000

\section{Pflügers Arch - Eur J Physiol (2000) Dol}

\subsection{7/s004240000401}

Due to an unfortunate error, the name of the first author was deleted from the HTML version when the proof corrections were carried out.

The online version of the original article can be found at http://dx.doi.org/10.1007/s004240000401

A.R. Chipperfield $(\bullet) \cdot$ A.A. Harper

Department of Anatomy and Physiology,

University of Dundee, DD1 4HN, UK

e-mail: a.r.chipperfield@dundee.ac.uk

Fax: +44-1382-345514

P.F-W. Chien · A. Gordon

Department of Obstetrics and Gynaecology,

University of Dundee, Ninewells Hospital and Medical School,

Dundee, DD1 9SY, UK

J.P.L. Davis

Department of Epidemiology and Public Health,

University of Dundee, Ninewells Hospital \& Medical School,

Dundee, DD1 9SY, Scotland, UK 